\title{
Classificação Climática de Thornthwaite para o Brasil com Base em Cenários de Mudanças Climáticas do IPCC-AR5
}

\author{
Antonio Duarte Marcos Junior ${ }^{1,2}$, Cleiton Da Silva Silveira ${ }^{1}$, \\ Francisco Das Chagas Vasconcelos Júnior ${ }^{2}$, Sullyandro Oliveira Guimarães ${ }^{2}$, \\ José Micael Ferreira Da Costa ${ }^{1,2}$ \\ ${ }^{1}$ Instituto de Engenharias e Desenvolvimento Sustentável, Universidade da Integração \\ Internacional da Lusofonia Afro-brasileira, Redenção, CE, Brasil. \\ ${ }^{2}$ Fundação Cearense de Meteorologia e Recursos Hídricos, Fortaleza, CE, Brasil.
}

Recebido em: 18 de Junho de 2017 - Aceito em: 2 de Abril de 2018

\begin{abstract}
Resumo
O objetivo deste trabalho é avaliar o balanço hídrico de Thornthwaite a partir das projeções do IPCC-AR5, identificando as possíveis mudanças de classificação climática projetada por este método. Foram consideradas as projeções de 14 modelos do CMIP5 para os cenários RCP 4.5 e RCP 8.5, para o período de 2010 a 2099, em comparação ao cenário histórico (1950 a 1999). A metodologia consiste na obtenção dos campos mensais de precipitação e temperatura próximo à superfície dos modelos climáticos. O balanço hídrico é realizado pelo método de Thornthwaite, considerando a ETP, os acumulados mensais de precipitação e os parâmetros de solo do Harmonized World Soil Database, sendo a classificação climática por região com base nas variáveis de saída do método. As projeções dos modelos apontam aumento da temperatura e ETP para as diferentes regiões do Brasil. As regiões Norte e Centro-Oeste apresentam aumento das áreas com climas mais áridos, enquanto a região Sul aponta para um aumento da área coberta por climas úmidos. Estas características podem representar aumento do escoamento superficial na região Sul e sua diminuição nas regiões Norte e Centro-Oeste. Tais mudanças representam um desafio a gestão de recursos hídricos, que deverá se adequar às futuras demandas e disponibilidades hídricas.
\end{abstract}

Palavras-chave: Mudanças Climáticas, IPCC, Classificação Climática.

\section{Thornthwaite Climate Classification for Brazil Under IPCC-AR5 Climate Change Scenarios}

\begin{abstract}
The objective of this work is to evaluate the Thornthwaite water balance approach from the IPCC-AR5 projections and to identify the possible changes in the climate classification projected by this method. For this purpose, the projections of 14 CMIP5 models from the scenarios RCP 4.5 and RCP 8.5, from 2010 to 2099, in comparison to the historical scenario (1950 to 1999). The methodology consists in obtaining the monthly surface precipitation and temperature near surface from the climate models. The water balance is performed by the Thornthwaite method considering the potential evapotranspiration (PET), the monthly rainfall and the soil parameters from the Harmonized World Soil Database over Brazil's regions. The regional climate classification was based on the output variables of the method. The projections from the models show indicate an increase in temperature and ETP for the different regions of Brazil. The Northern and Center-Western Brazil show an increase in the more arid climates, while the South Region points to an increase in humid climates. Such changes pose a challenge to water resources management, which should adapt to future demands and water availability.
\end{abstract}

Keywords: Climate Change, IPCC, Climate Classification.

Autor de correspondência: Antonio Duarte Marcos Junior, duarte.jr105@gmail.com 


\section{Introdução}

As mudanças climáticas podem produzir impactos significativos sobre os recursos hídricos e energéticos (IPCC, 2008; BANCO MUNDIAL, 2010; PBMC, 2012; Silveira et al., 2013; IPCC, 2014; Saboia et al., 2017). O aquecimento que vem sendo observado nas últimas décadas poderá acarretar mudanças no ciclo hidrológico, por meio de modificações dos padrões de precipitação e evapotranspiração, além de desencadear impactos diretos à umidade do solo, reservas subterrâneas e geração do escoamento superficial (IPCC, 2001; IPCC, 2007). Estes efeitos poderão exercer grande pressão nos hidrossistemas brasileiros (Fernandes et al., 2017), uma vez que também estão associados à projeção de aumento da demanda por água para as próximas décadas impulsionadas principalmente pelo crescimento populacional e aumento das riquezas.

O Painel Intergovernamental sobre Mudanças Climáticas (IPCC) aponta que a mudança do clima impõe uma grande ameaça ao desenvolvimento sustentável, por afetar de forma direta e indireta grande parte da população, nos seus mais diversos setores, como: saúde, recursos hídricos, infraestrutura urbana e rural, zonas costeiras, florestas e a biodiversidade, além dos setores que envolvem a economia - como agricultura, pesca, produção florestal, geração de energia, indústrias.

Além disso, o IPCC aponta impactos de grande magnitude sobre a América do Sul, em especial sobre recursos hídricos e setores econômicos relacionados. O que resulta em uma imposição ao governo brasileiro quanto à necessidade de formular e implementar medidas de mitigação e adaptação, com vistas a gerenciar riscos climáticos e responder de forma adequada aos prováveis impactos decorrente da mudança global do clima. Desta forma, torna-se fundamental a elaboração de subsídios ao planejamento nacional de longo prazo que incorpore medidas pró-ativas à mudança do clima.

A discussão de como o Brasil será afetado pelas mudanças no clima é fundamental para que medidas possam ser tomadas para tornar o país mais resiliente às condições climáticas do futuro ou mesmo à variabilidade do clima. Mediante a isso, muitos estudos estão sendo realizado a fim de gerarem, através de modelos globais do Clouped Model Intercomparison Project (CIMP), projeções que visem uma boa representatividade futura.

Análises nesse sentido podem ser realizadas utilizando modelos globais citados nos relatórios do IPCC, para diferentes cenários e variáveis climáticas, como por exemplo, precipitação, evapotranspiração, índice de aridez etc., como utilizado por Carril et al. (1997) em seus estudos. Contudo, existem incertezas inerentes aos modelos que precisam ser consideradas. A pequisa desenvolvida por Giorgi e Francisco (2000), sobre incertezas em simulações regionais de mudança climática para o século XXI, para diferentes cenários e diferentes regiões do mundo, e observaram que a fonte dominante de incerteza na simulação da mudança climática regional média deve-se à variabilidade entre modelos.

Diversos autores desenvolveram estudos recentes relacionados à América do Sul e voltados para o Brasil, utilizando modelos do CMIP, os quais identificam possíveis focos de mudanças climáticas (Bombardi e Carvalho, 2008; Torres e Marengo, 2012), indicadores de vulnerabilidade social (Torres et al., 2012; Darela Filho et al., 2016) e a frequência e intensidade de eventos extremos de chuva (Brito et al., 2014, Alves et al, 2017), por exemplo. Alguns dos resultados demonstram: uma maior exposição das regiões Norte, Nordeste, noroeste do estado de Minas Gerais, Centro-Oeste e cerrado às consequências de possíveis mudanças climáticas resultantes do aumento de gases do efeito estufa.

Vera et al. (2006) utilizaram em seu estudo um subconjunto de simulações climáticas do século $\mathrm{XX}$ do Quarto Relatório do IPCC (IPCC-AR4) para avaliar a capacidade desses modelos de reproduzir a precipitação sazonal climatológica observada na América do Sul durante o período de 1970 - 1999. Seus resultados mostraram que os modelos são capazes de reproduzir as principais características do ciclo de precipitação sazonal sobre a América do Sul, mesmo em meio às incertezas (Vera et al., 2006).

O estudo realizado por Marengo e Valverde (2007) fez uma análise dos cenários de climas futuros (até 2010) para o Brasil como um todo e para as regiões Nordeste, Amazônica e Bacia do Prata, gerados pelos modelos usados no IPCC-AR4. Silveira et al. (2013) utilizou, para as mesmas regiões citadas, os modelos globais do CMIP5, analisando as projeções de precipitação do cenário RCP8.5 para o século XXI. Os resultados desses estudos indicam: para a região Nordeste, tendência de redução de chuvas acompanhada de aumento da temperatura para finais do século XXI, porém os modelos divergem quanto ao sinal da anomalia; na região Amazônica, os modelos sugerem maiores possibilidades de redução na precipitação; na região do Prata, o conjunto dos modelos projeta poucas alterações, contudo alertam para as elevadas temperaturas do ar que poderiam comprometer a disponibilidade de água.

Estudos como esses demonstram uma preocupação crescente da comunidade científica quanto às alterações do clima e suas inerentes consequências, que podem ser agravadas quando pensadas a longo prazo. O Brasil poderá ser afetado nas suas mais diferentes esferas, acarretando diversos danos que precisam ser levados em consideração, para o devido planejamento preventivo e mitigador. Conhecer o país e suas características é importante para este processo.

A vazão média anual dos rios em território brasileiro é de $179 \mathrm{mil} \mathrm{m}^{3} / \mathrm{s}$, o que corresponde a aproximadamente 
$12 \%$ da disponibilidade hídrica superficial mundial (Shiklomanov, 1998). A variação do escoamento nos rios é influenciada por diversos fatores, entre os quais se destacam a precipitação ocorrida na bacia de contribuição e as mudanças no uso e ocupação do solo. No Brasil, a precipitação média anual (histórico de 1961-2007) é de $1.761 \mathrm{~mm}$, variando de valores na faixa de $500 \mathrm{~mm}$ na região semiárida do Nordeste a mais de $3.000 \mathrm{~mm}$ na região Amazônica (ANA, 2013).

O Brasil é o país que possui a matriz energética com maior participação de fontes renováveis do mundo, onde as mesmas correspondem a $41,2 \%$ da oferta interna de energia do país (EPE, 2016). As principais fontes renováveis são a biomassa da cana-de-açúcar e a hidráulica, com $16,9 \%$ e $11,3 \%$, respectivamente, do total da oferta de energia interna (EPE, 2016). Estas fontes dependem das condições climáticas, que podem alterar sua disponibilidade. Contudo, no Brasil, quanto ao planejamento energético de longo prazo, não é recorrente levar-se em consideração os impactos que as mudanças climáticas poderão causar no setor energético (Schaeffer et al., 2008).

Além disso, há uma tendência de aumento da demanda pela água da irrigação no Brasil que pode levar à diminuição da segurança alimentar e maior vulnerabilidade para agricultores rurais, especialmente nas regiões semiáridas. Os impactos diretos do clima sobre a produção e a distribuição da produção agrícola no país são apenas alguns dos efeitos econômicos causados pela mudança no clima. Esses impactos propagam-se nos diversos setores econômicos (Domingues et al., 2011), como por exemplo, aumentando o custo de produção agrícola e da pecuária, e elevando o custo dos insumos para o setor de alimentos e para o consumo das famílias.

Portanto, o objetivo deste trabalho consiste em avaliar o balanço hídrico Thornthwaite (1948), a partir das projeções do IPCC-AR5 e identificar as possíveis mudanças de classificação climática projetada pelo método para todo Brasil.

\section{Material e Métodos}

O estudo foi realizado para as cinco regiões geográficas do Brasil: Centro-Oeste, Norte, Nordeste, Sul e Sudeste. Para cada uma destas foram analisados como a evolução dos tipos climáticos decorre ao longo do século XXI de acordo com as projeções feitas pelos diferentes modelos do IPCC-AR5. Os tipos climáticos seguem o Sistema de Classificação Climática (SCC) de Thornthwaite. Esta seção resume os procedimentos utilizados para a obtenção desta classificação climática. A metodologia divide-se, basicamente, em quatro etapas (conforme Fig. 1):

- A primeira etapa consistiu na obtenção dos campos de precipitação dos modelos globais do IPCC-AR5 para os cenários Historical, RCP 4.5 e RCP 8.5 sobre o Brasil, e então realizada a correção estatística do viés. Essa correção utilizou como base de dados de precipitação mensal do "University of East Anglia"(UEA, 2015)/ "Climate Research Unit"'(CRU, 2015). Para período de referência (histórico) utilizou-se a série mensal de 1950 a 1999, enquanto para as projeções foi considerado o período de 2010 a 2098. Maiores detalhes sobre os modelos globais utilizados podem ser encontrados na seção 2.1;

- Na segunda etapa foram obtidas as evapotranspirações potenciais médias mensal a partir dos modelos globais do IPCC-AR5 para os cenários Historical, RCP 4.5 e RCP 8.5, usando o método de Hargreaves e Samani (1985). Para tanto são usados como dados de entrada as temperaturas máxima, mínima e média dos modelos

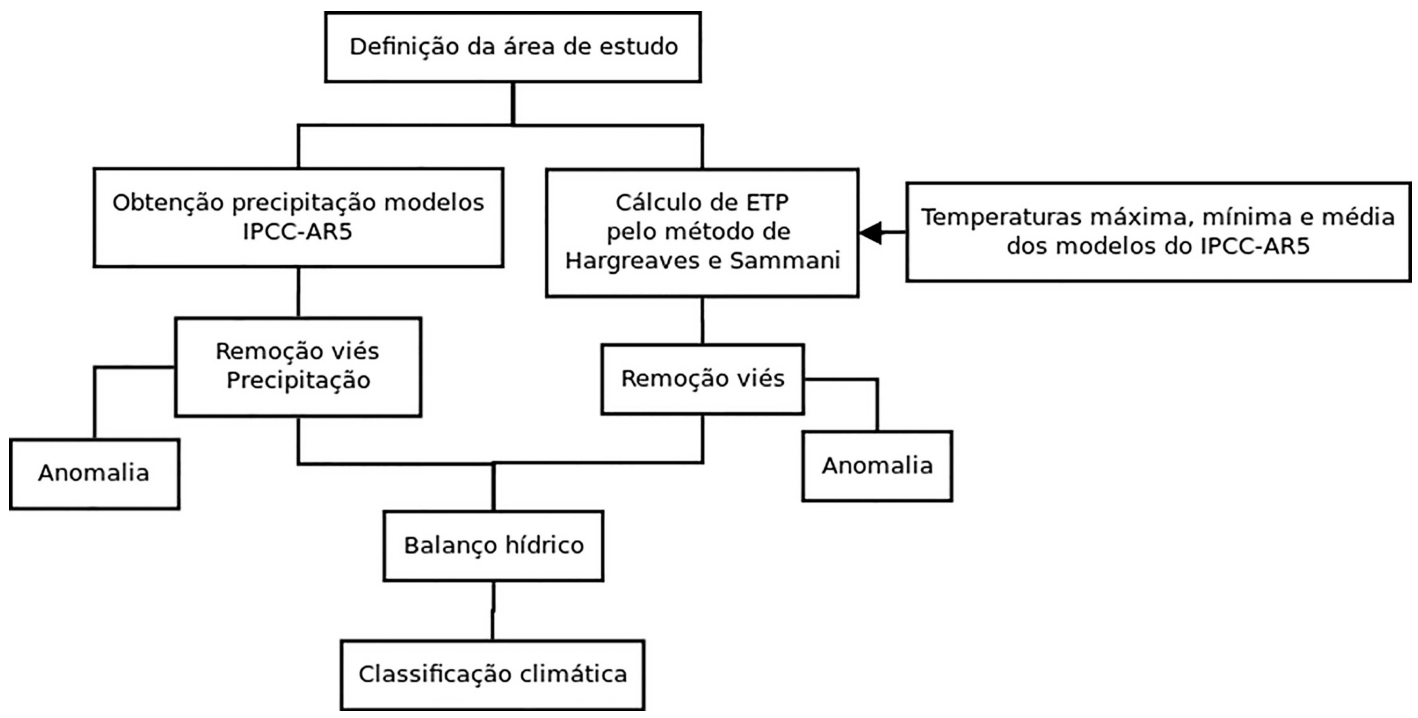

Figura 1 - Metodologia utilizada. 
globais do IPCC-AR5. Na sequência foi realizada a correção estatística do viés, similar àquela feita para a precipitação, sendo a evapotranspiração potencial utilizada obtida pelas variáveis do CRU (UEA, 2015).

- Na terceira etapa realizou-se o balanço hídrico pelo método de Thornthwaite, utilizando como dados de entrada as evapotranspirações estimadas e as precipitações com viés removido, e as componentes do solo obtidas através do Harmonized World Soil Database (HWSD) para o Brasil;

- A quarta etapa consiste em realizar a classificação climática de Thornthwaite para a base de dados do CRU e para os diferentes cenários e modelos globais do IPCCAR5.

\subsection{Dados utilizados}

Com a intenção de representar as condições climáticas históricas sobre o Brasil e remover o viés das variáveis meteorológicas modeladas, foram utilizados dados observacionais da "University of East Anglia"/"Climate Research Unit"(CRU). Os dados do CRU foram utilizados por estarem disponíveis, com integridade espacial e temporal, e sua base de dados disponibiliza valores de temperaturas máxima, média, mínima e precipitação. O período de 1950 a 1999 foi escolhido como referencial histórico por compreender a toda a série histórica dada pelos modelos do IPCC.

Para o AR5 do IPCC foram estabelecidos cenários para estudar as possíveis mudanças decorrentes das ações antrópicas, que servem também para orientar os Centros de Meteorologia Global a fazerem simulações padronizadas possibilitando a intercomparação dos resultados. Para tanto se tem o cenário historical - que traz condições similares ao que foi observado para o clima presente, e os cenários futuros com rotas representativas de concentração de gases do efeito estufa (RCPs): RCP 2.6, 4.5, 6.0 e 8.5, que correspondem a concentrações médias de 450, 650, 850 e 1370 ppm de CO2eq, respectivamente (Van Vuuren et al., 2011; Taylor et al., 2012; Flato et al., 2013). Nas análises, foram utilizados os resultados de 14 modelos de circulação geral da atmosfera (Tabela 1), para o Historical no estudo do clima recente, e para os RCP4.5 e RCP8.5 com o objetivo de averiguar as mudanças no clima.

As séries temporais foram divididas em quatro períodos: o primeiro denominado como período histórico, (1950 à 1999), servindo de referência para a análise da evolução dos tipos climáticos nas regiões de estudo; os demais períodos referem-se às projeções para o presente século divididos de 2010 a 2039, 2040 a 2069 e 2070 a 2099.

\subsection{Evapotranspiração potencial}

O SCC de Thornthwaite (Thornthwaite, 1948) faz a classificação climática a partir do balanço hídrico, o qual utiliza como variáveis de entrada: precipitação, evapotranspiração e capacidade de água disponível no solo (CAD). Dentre os diversos modos existentes para se calcular a evapotranspiração potencial o escolhido foi o de Hargreaves e Samani (1982). A escolha se deu, principalmente, devido à quantidade de variáveis disponíveis

Tabela 1 - Modelos utilizados e suas respectivas instituições e países.

\begin{tabular}{|c|c|c|}
\hline Modelo & Grupo (ou centro) de modelagem & País \\
\hline ACCESS1-0 & Commonwealth Scientific and Industrial Research Organization (CSIRO) and Bureau of Meteorology (BOM) & Austrália \\
\hline \multicolumn{3}{|l|}{ ACCESS1-3 } \\
\hline BCC-CSM-1-1 & Beijing Climate Center, China Meteorological Administration & China \\
\hline CESM1-BGC & Community Earth System Model Contributors & $\begin{array}{l}\text { Estados } \\
\text { Unidos }\end{array}$ \\
\hline CanESM2 & Canadian Centre for Climate Modelling and Analysis & Canadá \\
\hline CNRM-CM5 & $\begin{array}{c}\text { Centre National de Recherches Metéorologiques / Centre Européen de Recherche et Formation Avancée en Calcul } \\
\text { Scientifique }\end{array}$ & França \\
\hline IPSL-CM5A-MR & Institut Pierre-Simon Laplace & França \\
\hline \multicolumn{3}{|l|}{ IPSL-CM5B-LR } \\
\hline CSIRO-Mk3-6-0 & $\begin{array}{l}\text { Commonwealth Scientific and Industrial Research Organization in collaboration with Queensland Climate Change } \\
\text { Centre of Excellence }\end{array}$ & Austrália \\
\hline HadGem2-AO & National Institute of Meteorological Research/Korea Meteorological Administration & Coréia do Sul \\
\hline MIROC5 & $\begin{array}{l}\text { Atmosphere and Ocean Research Institute (The University of Tokyo). National Institute for Environment Studies, } \\
\text { and Japan Agency for Marine-Earth Science and Technology }\end{array}$ & Japão \\
\hline $\begin{array}{l}\text { MIROC-ESM } \\
\text { MIROC-ESM- } \\
\text { CHEM }\end{array}$ & $\begin{array}{l}\text { Japan Agency for Marine-Earth Science and Technology, Atmosphere and Ocean Research Institute (The University } \\
\text { of Tokyo), and National Institute for Environmental Studies. }\end{array}$ & Japão \\
\hline MPI-ESM-LR & Max-Planck-Institut for Meteorologie (Max Planck Institute for Meteorology) & Alemanha \\
\hline
\end{tabular}


para o cálculo. Neste método, a evapotranspiração potencial pode ser estimada a partir da Eq. (1):

$$
E T P=0,0023\left(T_{\text {med }}+17,8\right) *\left(T_{\max }-T_{\min }\right)^{1 / 2} R_{a} * 0,4081
$$

em que: ETP: é a taxa de evapotranspiração potencial $\left(\mathrm{mm} . \mathrm{dia}^{-1}\right) ; T_{\text {med }}$ : temperatura média do ar $\left({ }^{\circ} \mathrm{C}\right) ; T_{\max }$ : temperatura máxima do ar $\left({ }^{\circ} \mathrm{C}\right) ; T_{m i n}$ : temperatura mínima do $\operatorname{ar}\left({ }^{\circ} \mathrm{C}\right) ; R_{a}$ : a radiação solar no topo da atmosfera $(\mathrm{mm}$. $\left.\operatorname{dia}^{-1}\right)$.

A radiação solar foi estimada em função da distância relativa entre a Terra e o Sol, na latitude do ponto de estudo. $\mathrm{O}$ valor 0,408 corresponde ao fator de conversão de MJ.m ${ }^{2} \cdot d^{-1}$ para mm.dia ${ }^{-1}$.

\subsection{Remoção de viés}

Muito do conhecimento sobre mudanças climáticas depende dos modelos de circulação global (GCM) porém um dos principais problemas dessas projeções é o viés dos modelos climáticos (Volosciuk et al., 2017). Estudos de impacto raramente usam os GCMs diretamente porque os erros nas simulações em relação às observações históricas são elevados (Ramirez-Villegas et al., 2013). Em geral os modelos têm uma resolução baixa, as quais não satisfazem os requisitos de estudo de impactos em pequenas regiões (Navarro-Racines et al., 2015). Para estudos de impactos climáticos torna-se necessário a remoção do viés dos mesmos (Turco et al., 2015). A remoção de viés foi feita para as séries de precipitação e evapotranspiração, utilizando os dados observados pelo CRU através da Eq. (2).

$$
X_{c o r}=\frac{\left(x_{m}-\bar{x}_{m}\right)}{S_{m}} * S_{o b s}+\bar{x}_{o b s}
$$

em que $X_{c o r}$ é a variável corrigida, $X_{m}$ é o valor da variável original do modelo, $x_{m}$ é a média do modelo, $S_{m}$ é o desvio padrão do modelo, $x_{o b s}$ e $S_{o b s}$ são, respectivamente, a média e o desvio padrão observados.

\subsection{Balanço hídrico}

O balanço hídrico foi calculado utilizando-se a versão simplificada do método de Thornthwaite e Mather (1955) proposta por Rossato (2001) dada pela Eq. (3):

$$
A_{t+1}=A_{t}+P R_{t}-E T R_{t}
$$

em que $A$ o armazenamento de água no solo (mm), $P R$ a precipitação $(\mathrm{mm})$, ETR a evapotranspiração real e $t$ o tempo, ou seja, o volume de água armazenado no solo, para um tempo futuro, depende das condições hídricas atuais.

A ETR é estimada fazendo a seguinte consideração: caso a soma dos volumes precipitado (PR) e retido no solo (A), em um período de tempo t, sejam maiores que a Evapotranspiração Potencial (ETP) do período a ETR será a própria ETP caso contrário a ETR será a soma de PR e A do período.
Outra variável utilizada no balanço hídrico é a capacidade de água admissível no solo (CAD), esta variável representa a quantidade máxima de água que o solo pode reter antes de ficar saturado e produzir escoamento. Neste trabalho foram utilizados os valores de CAD fornecidos pelo Harmonized World Soil Database (HWSD) disponibilizado pela Organização das Nações Unidas para a Alimentação e Agricultura (FAO - Food and Agriculture Organization of the United Nations) (Wieder et al., 2014). $\mathrm{O}$ escoamento superficial é, portanto, a diferença entre o volume de água disponível para o solo $\left(\mathrm{A}_{\mathrm{t}+1}\right)$ e a CAD.

\subsection{Sistema de classificação climática de Thornthwaite}

O SCC proposto por Thornthwaite classifica o clima de uma região em função do seu índice de umidade. Sendo este uma variável que depende do índice hídrico e o índice de aridez. O índice hídrico é dado pela Eq. (4) e representa a disponibilidade de água. O índice de aridez, dado pela Eq. (5), indica a deficiência hídrica da região:

$$
\begin{gathered}
I_{h}=\left(\frac{E X C}{E T P}\right) * 100 \\
I_{a}=\left(\frac{D E F}{E T P}\right) * 100
\end{gathered}
$$

em que $E X C$ é o excedente hídrico, ou seja, a quantidade de água que excede a capacidade de armazenamento no solo e torna-se escoamento superficial. DEF é a deficiência hídrica do solo, sendo a quantidade de água que poderia ser evapotranspirada mas não foi devido a quantidade de água disponível no solo ser menor do que a evapotranspiração potencial.

A partir dos dois índices citados é calculado o índice de umidade do solo que é obtido segundo a Eq. (6).

$$
I_{u}=I_{h}-0,6 I_{a}
$$

A partir do índice de umidade do solo, o clima da região em estudo é classificado conforme um dos nove tipos climáticos mostrados na Tabela 2.

\section{Resultados e Discussão}

Os modelos mostram que em ambos os RCP's há aumento da temperatura em todas as regiões brasileiras. Para o cenário RCP8.5, os efeitos na temperatura são maiores, principalmente no último período de 30 anos do século XXI, onde a anomalia de temperatura é superior a $3,5^{\circ} \mathrm{C}$ para a maioria dos modelos e para todas as regiões (Fig. 2).

A mediana das anomalias de temperatura é de aproximadamente $1,2{ }^{\circ} \mathrm{C}$ no período de 2010 a 2039 para os cenários RCP4.5 e RCP8.5 nas regiões Nordeste e 
Tabela 2 - Classificação do clima segundo o Índice de umidade.

\begin{tabular}{lc}
\hline Tipos climáticos & Índice de umidade \\
\hline A - Superúmido & $100 \leq \mathrm{Iu}$ \\
B4 - Úmido & $80 \leq \mathrm{Iu}<100$ \\
B3 - Úmido & $60 \leq \mathrm{Iu}<80$ \\
B2 - Úmido & $40 \leq \mathrm{Iu}<60$ \\
B1 - Úmido & $20 \leq \mathrm{Iu}<40$ \\
C2 - Sub-úmido & $0 \leq \mathrm{Iu}<20$ \\
C1 - Sub-úmido seco & $-20 \leq \mathrm{Iu}<0$ \\
D - Semiárido & $-40 \leq \mathrm{Iu}<-20$ \\
E - Árido & $-60 \leq \mathrm{Iu}<-40$ \\
\hline
\end{tabular}

Fonte: Thornthwaite (1948).
Sudeste e deslocou-se na direção positiva nos demais períodos. Enquanto no Norte e no Centro-Oeste o impacto nessa variável é mais intenso, com a mediana das anomalias aproximadamente igual a $1,5^{\circ} \mathrm{C}$. Enquanto no Sul a magnitude da anomalia é inferior às demais regiões do país, próximo a $1,0^{\circ} \mathrm{C}$.

$\mathrm{Na}$ Fig. 3 são mostradas as anomalias de precipitação dos modelos do CMIP5 nas diferentes regiões do Brasil, em três períodos do século XXI: 2010 a 2039, 2040 a 2069 e 2070 a 2098. Os modelos divergem quanto ao futuro da precipitação para os cenários RCP4.5 e RCP8.5. Entretanto, as medianas das anomalias indicam que as regiões Norte e Nordeste, para ambos cenários, podem sofrer diminuição das precipitações ao longo do século,

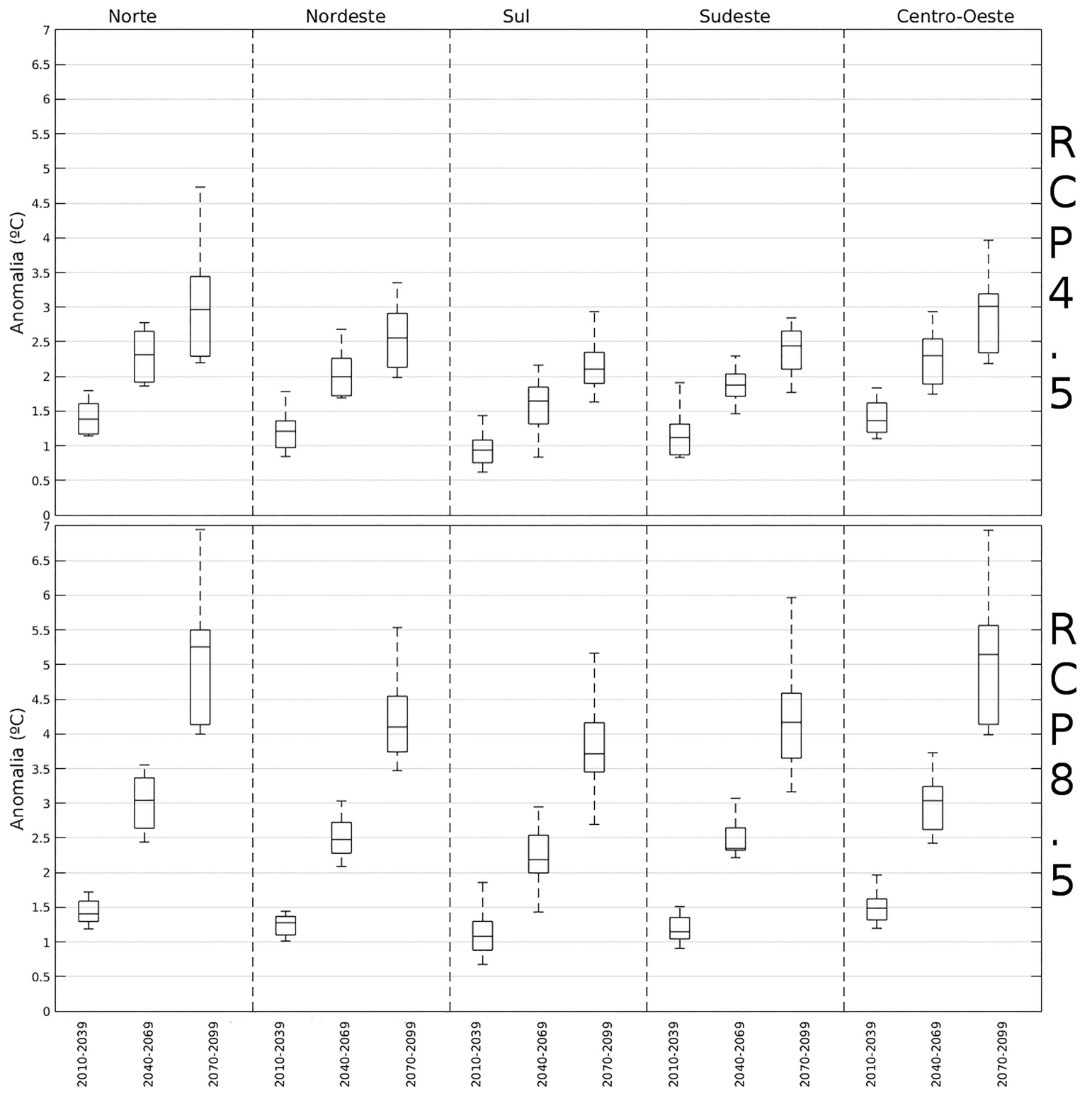

Figura 2 - Anomalia de temperatura para os modelos do CMIP5 para as cinco regiões do Brasil referentes aos cenários RCP4.5 e RCP8.5 para os períodos 2010-2039, 2040-2069 e 2070-2099. 


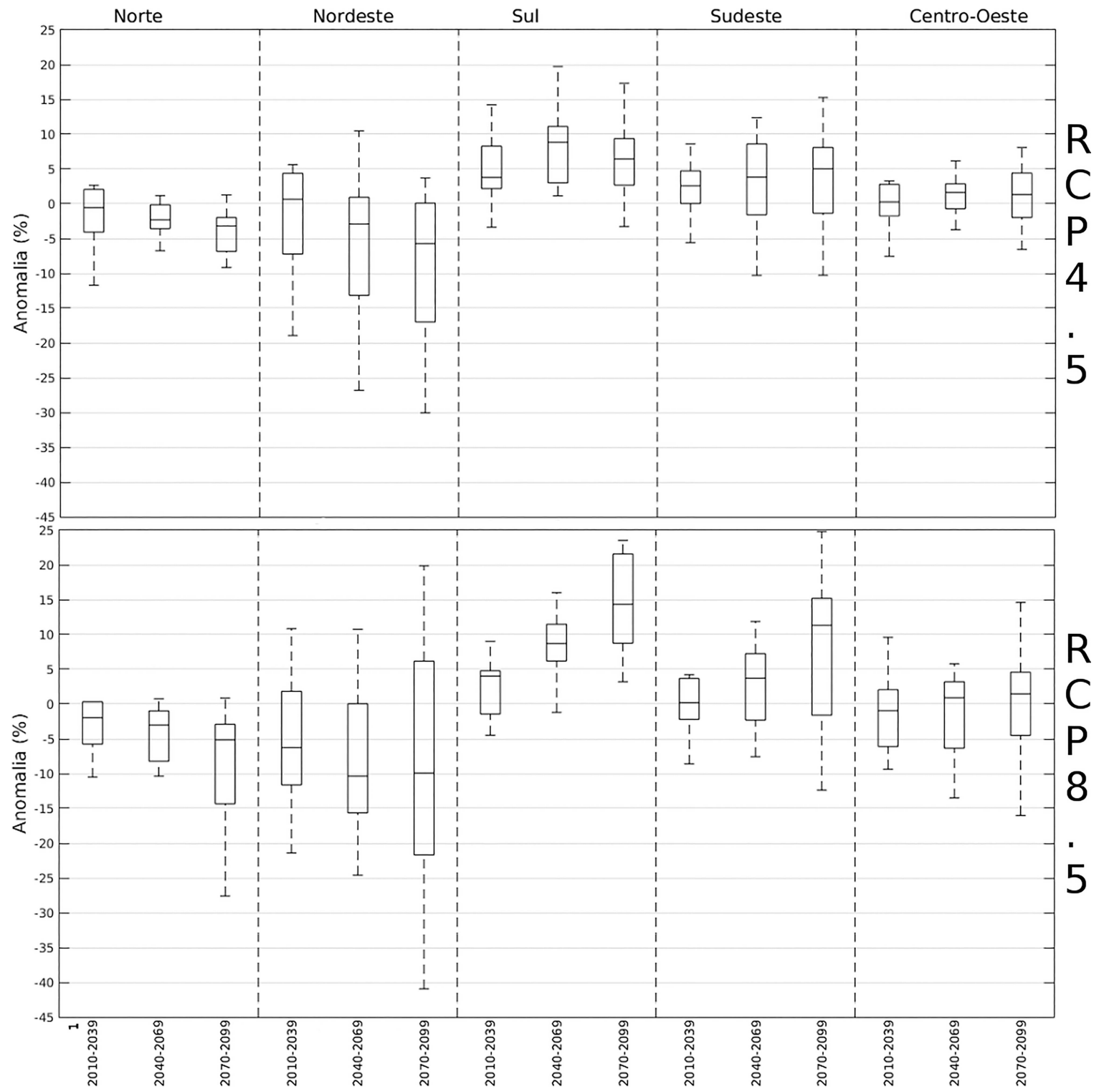

Figura 3 - Anomalia de percentual de precipitação para os modelos do CMIP5 para as cinco regiões do Brasil referentes aos cenários RCP4.5 e RCP8.5 para os períodos 2010-2039, 2040-2069 e 2070-2099.

enquanto que indicam maior possibilidade da ocorrência de anomalias positivas de precipitação no Sul e Sudeste do país. Na região Centro-oeste a mediana se apresenta em torno da média nos três períodos avaliados. A incerteza das projeções é verificada com a intensificação das emissões de gases do efeito estufa, visto que há um aumento da divergência entre os modelos no cenário RCP8.5 em comparação ao RCP4.5.

Os modelos mostram maiores divergências no último período do século, porém indicam uma intensificação do sinal da anomalia de precipitação mostrada nos períodos anteriores, apresentando reduções significativas principalmente na região Nordeste do país, onde alguns modelos tiveram até $-40 \%$ para o RCP 8.5 e $-30 \%$ para o RCP4.5 (Fig. 3).
A mediana das anomalias de precipitação para o RCP4.5 apresenta valores de entre $-5 \%$ e $5 \%$ no período de 2010 a 2039 . Para o período de 2040-2069, projeta-se reduções nas precipitações nas Regiões Norte e Nordeste, com alguns modelos indicando diminuições nos valores médios anuais dessa variável em até $27 \%$ no Nordeste do país. Enquanto que para as demais regiões analisadas a maioria dos modelos indica aumento nas médias anuais de chuvas. Já para o RCP8.5 as medianas variam de $-10 \%$ (Região Nordeste) a 8,5\% (Região Sul). Para o período de 2070-2099 aumentam-se as incertezas entre os modelos, as quais variam entre $-40 \%$ e $20 \%$ para a Região Nordeste.

Além disso, as projeções apontam para aumento gradativo da evapotranspiração potencial em todas as regiões brasileiras, sinal semelhante ao encontrado para a 
temperatura média anual (Fig. 4). O cenário RCP 8.5 possui anomalias de ETP com maior magnitude, principalmente nos últimos 30 anos analisados. Ao longo do século, a projeção do cenário RCP4.5 indica que o conjunto de modelos apresenta maior divergência sobre as regiões Sul e Norte do que para as outras regiões do Brasil. Esta característica é apontada em decorrência das incertezas associadas com as diferentes representações da biosfera, dada a complexidade dos biomas nessas regiões, e dificuldades enfrentadas pelos esquemas de superfície dos modelos climáticos.

No meio do século a incerteza associada ao conjunto dos modelos, da RCP 4.5, para a ETP tem maiores acréscimos na região Sul do que na região Norte, em relação ao período histórico. Este resultado é coerente com as projeções de acréscimo de precipitação na porção sul do país e decréscimo no norte devido ao aumento da diferença de disponibilidade hídrica e aumento generalizado de temperatura próximo à superfície. O cenário $\mathrm{RCP} 8.5$ também indica maior espalhamento das projeções de ETP nas regiões Sul e Norte para a metade e final do século. As diferenças encontradas podem estar associadas com a forma que os modelos representam o feedback na vegetação, impulsionado pela maior oferta de carbono na atmosfera (Arora et al., 2013).

A classificação climática com os dados do CRU mostrou um padrão de distribuição de tipos climáticos semelhantes ao encontrado na literatura (Cavalcanti et al.,

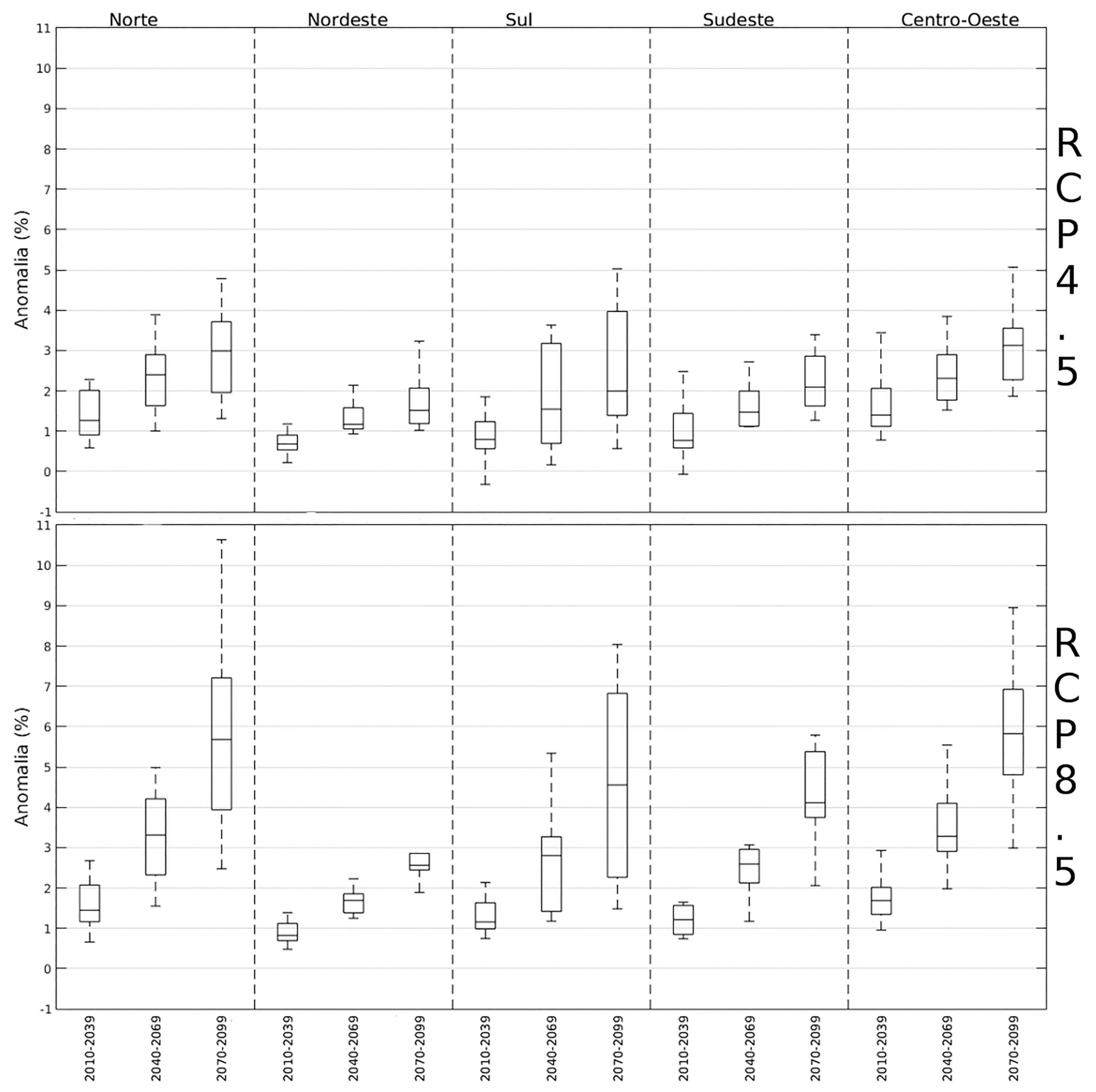

Figura 4 - Anomalia de percentual de evapotranspiração potencial para os modelos do CMIP5 para as cinco regiões do Brasil referentes aos cenários RCP4.5 e RCP8.5 para os períodos 2010-2039, 2040-2069 e 2070-2099. 


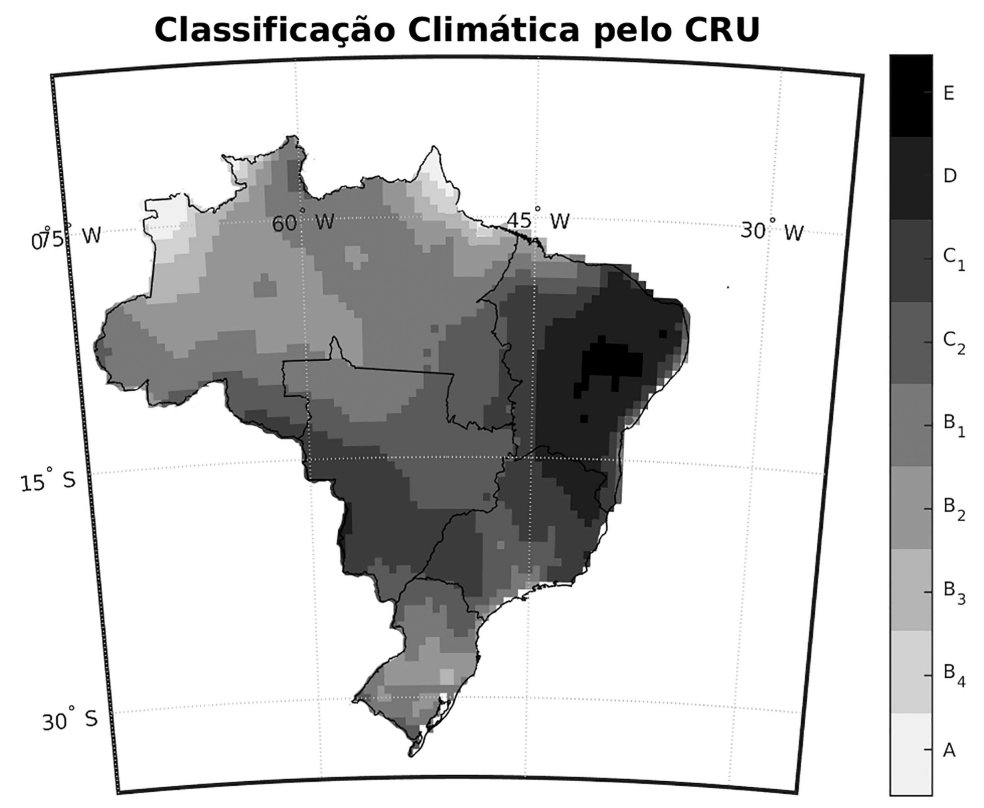

Figura 5 - Classificação climática segundo os dados do CRU.

2009). Esta análise demonstra que a metodologia aplicada consegue representar bem a distribuição de climas ao longo do território brasileiro. Por exemplo, a região Nordeste apresenta climas com maior índice de aridez e as regiões Norte e Sul climas mais úmidos (Fig. 5).

Após a remoção de viés os modelos apresentam distribuição espacial semelhante de tipos climáticos ao CRU, entretanto tendem a mostrar uma maior área coberta por climas áridos tipo E na região Nordeste do Brasil. Entre os modelos analisados dois se destacam: o CanESM2, por mostrar cenário mais áridos, e o IPSL-CM5A-MR, por mostrar cenários mais úmido (Fig. 6).

A região Centro-Oeste é uma região com prevalência de climas intermediários, prevalecendo o tipo climático C1 (sub-úmido) seco, onde a maioria dos modelos mostram entre 40 e $50 \%$ do território com tal classificação. No cenário médio de emissões (RCP4.5) é mais provável uma maior redução da cobertura do tipo $\mathrm{C} 1$ na região (redução que pode chegar a ficar entre -25 e $-30 \%$ ). Alguns modelos apontam para aumentos expressivos da área coberta pelo clima $\mathrm{D}$, em especial na metade do século, podendo chegar a $+30 \%$ em alguns casos, indicando aumento das regiões com clima semiárido. Além disso, a maioria dos modelos concordam com a redução das áreas cobertas pelo clima úmido B1, refletido no aumento do tipo climático $\mathrm{C} 2$ - variando entre $+5 \%$, no início do século, a $+15 \%$, no final.

O mesmo padrão é observado no cenário RCP8.5 para o clima $\mathrm{C} 1$. O clima D, em especial no final do século, é apontado na maioria dos modelos para um aumento da área coberta. Destaca-se também a redução da cobertura do clima B1 associado ao aumento de $\mathrm{C} 2$. As alterações observadas nos cenários indicam uma tendência de aumento de aridez no Centro-Oeste. É provável que a cobertura de climas mais amenos tenha diminuição na região central do Brasil, com maior probabilidade de evolução tênue das áreas com clima do tipo semiárido D.

A região Nordeste do país é a mais árida do território brasileiro e considerada um das mais propícias a problemas com as mudanças climáticas, possuindo prevalência de climas áridos e semiáridos (Lima et al, 2011), conforme Fig. 8, onde pelo menos $5 \%$ da região é coberto por clima classificado como úmido (B1). No período histórico os modelos possuem dificuldade de representar os campos meteorológicos da região devido a complexidade climática. Em média, os modelos classificam pelo menos $40 \%$ na categoria $\mathrm{E}$ (clima árido) no período histórico e $30 \%$ na classe $\mathrm{D}$ (clima semiárido), podendo estar associado à baixa resolução dos modelos climáticos, implicando na perda de capacidade em representar heterogeneidades da topografia, vegetação e regiões costeiras, somadas às limitações intrínsecas à discretização das equações físicas.

As projeções para ambos os cenários apontam para uma diminuição de clima $\mathrm{C} 2$ até o final do século sobre o Nordeste brasileiro, podendo alcançar um decréscimo de $25 \%$. Enquanto isto os climas D e E poderão avançar sobre o território desta região, reduzindo a disponibilidade de água e possivelmente tornando difícil o cultivo de algumas culturas agrícolas típicas da região, o que poderia agravar os conflitos pelo uso de água na região, podendo agravar ainda mais os conflitos pelo uso de água.

A região Norte tem a maior cobertura de climas úmidos do país com prevalência dos climas B1 e C cobrindo cerca de $50 \%$ e $45 \%$ da região, respectivamente, 
conforme Fig. 9. Nesta região os modelos apontam para uma expressiva diminuição da cobertura dos dois tipos climáticos predominantes na região em especial no cenário RCP 8.5 , onde todos os modelos apontam para uma
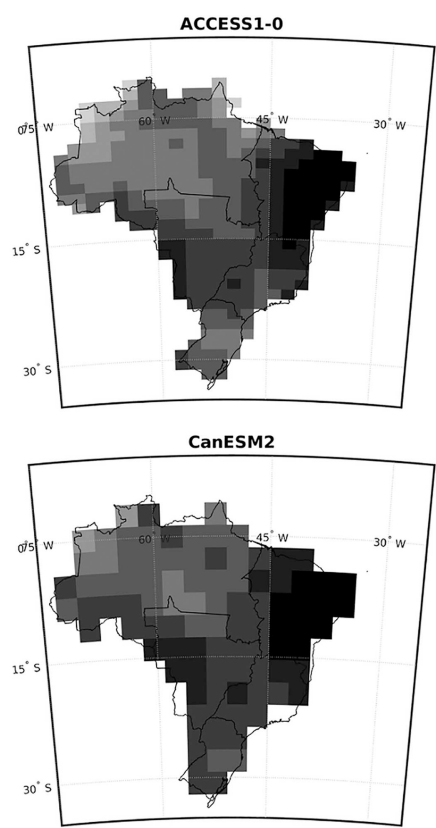

CSIRO-Mk3-6-0

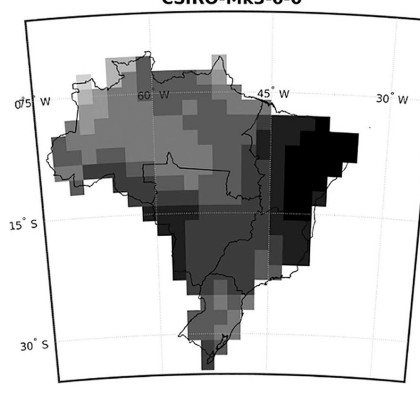

IPSL-CM5B-LR

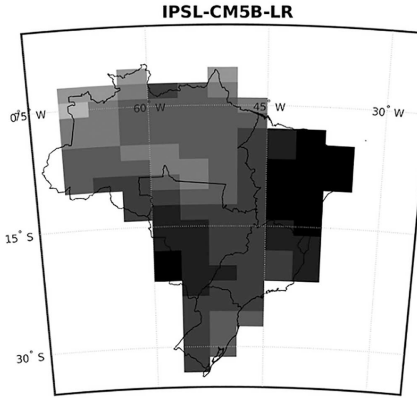

MIROC $_{E}$ SM

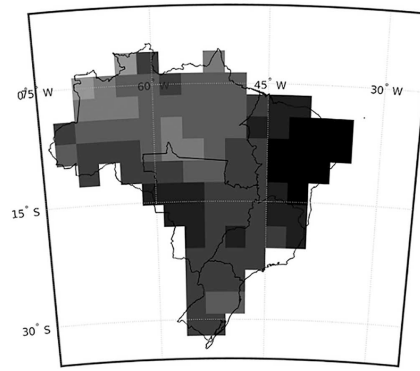

ACCESS1-3

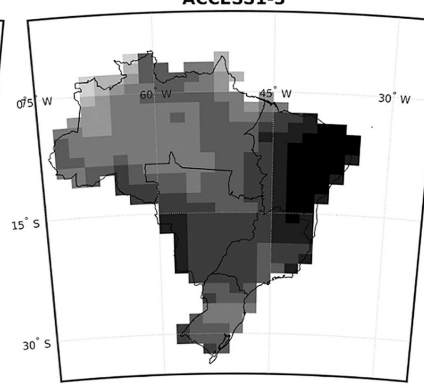

CESM1-BGC

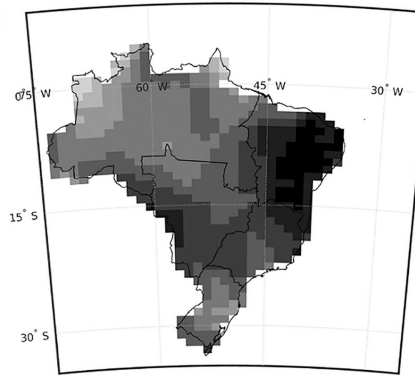

HadGEM2-AO

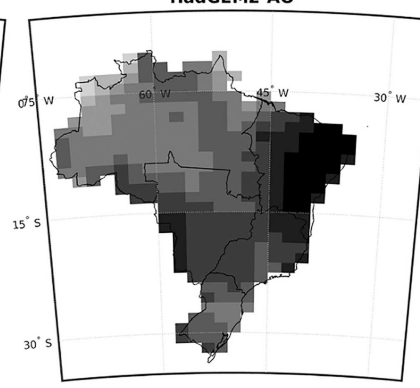

MIROC5

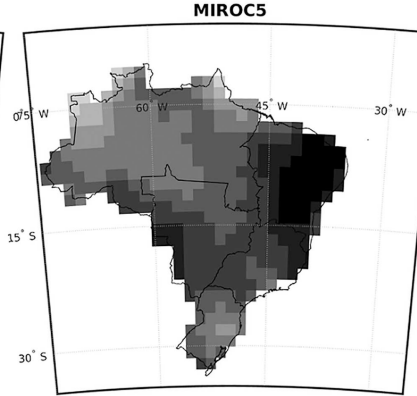

MPI-ESM-LR

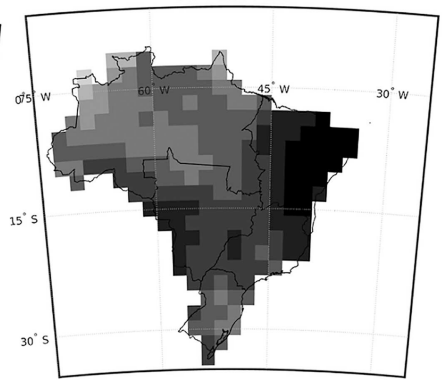

bcc-csm1-1

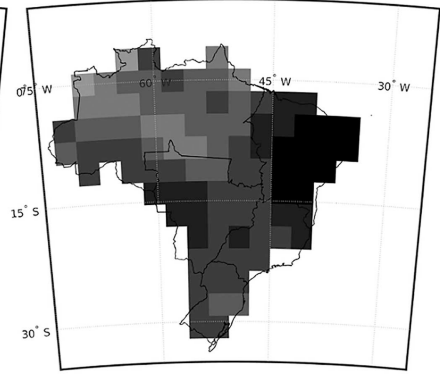

CNRM-CM5

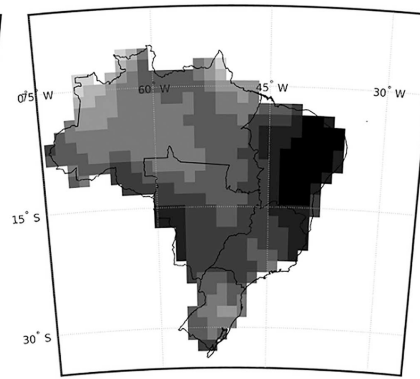

IPSL-CM5A-MR

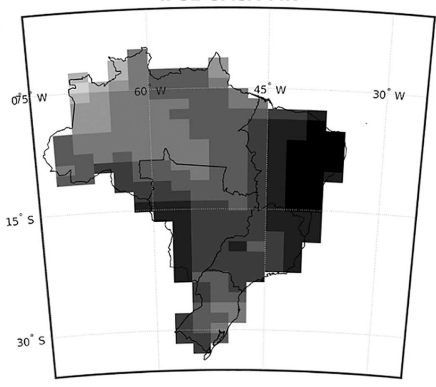

MIROC-ESM-CHEM

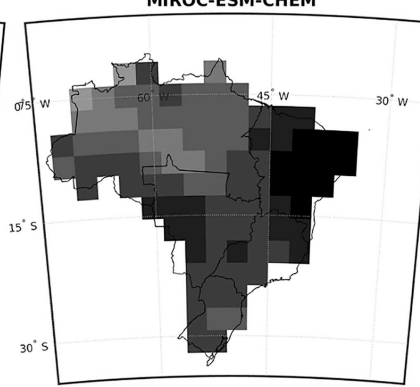

$B_{3}$

$B_{4}$

A

Figura 6 - Classificação climática para o período histórico (1950-1999) segundo os modelos do IPCC. 

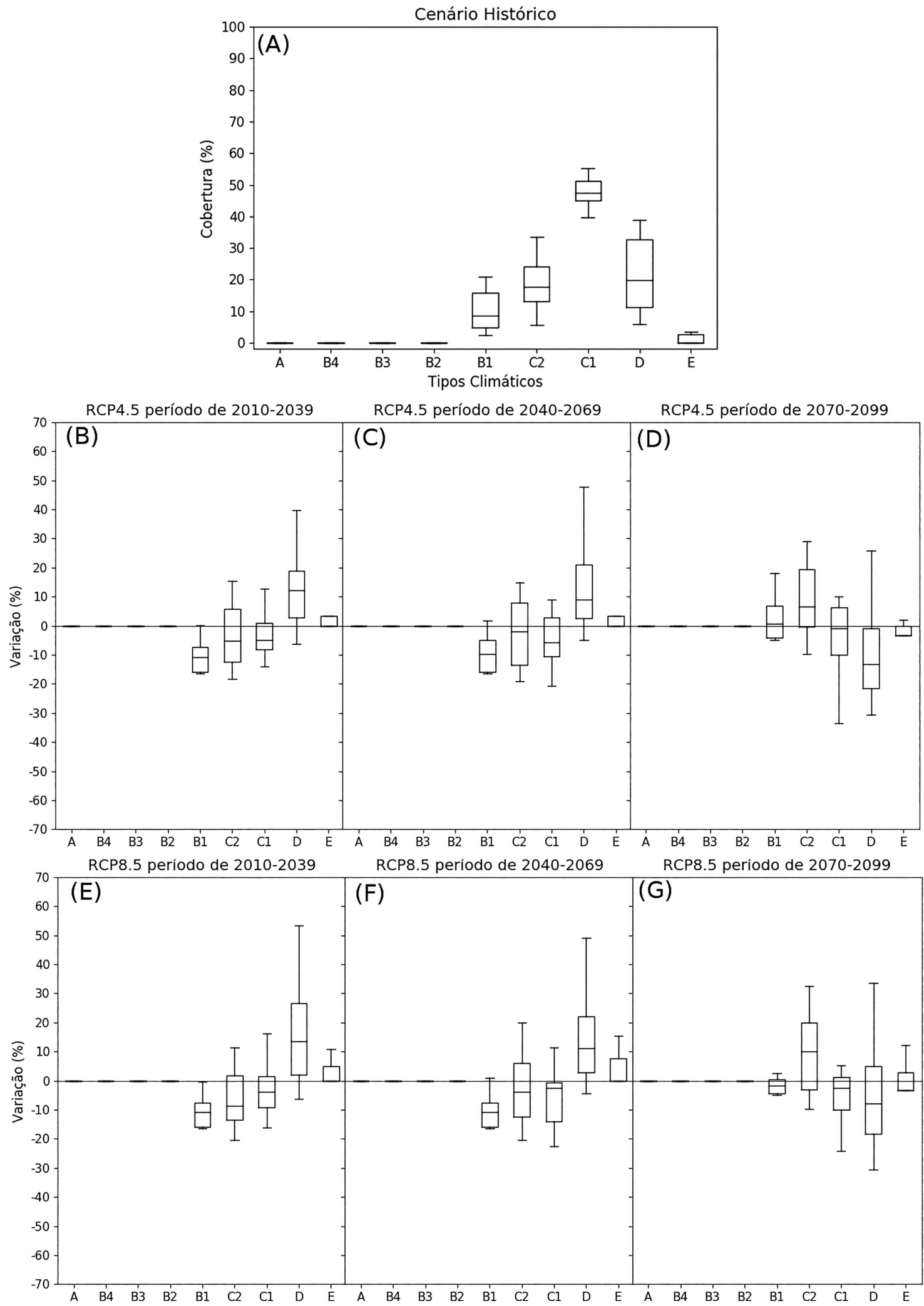

Figura 7 - Variação dos tipos climáticos na região Centro-Oeste. (a) Área percentual de Cobertura de cada tipo de clima. Anomalia da área percentual coberta por cada tipo de clima no cenário RCP 4.5 (P45-PXX) para os períodos: (b) 2010-2039; (c) 2040-2069 e (d) 2070-2098. Anomalia da área percentual coberta por cada tipo de clima no cenário RCP 8.5 (P85-PXX) pelo para os períodos: (e) 2010-2039; (f) 2040-2069 e (g) 2070-2098. Onde PXX, P45 e P85 representam área percentual coberta por cada tipo de clima em cada período do século. 

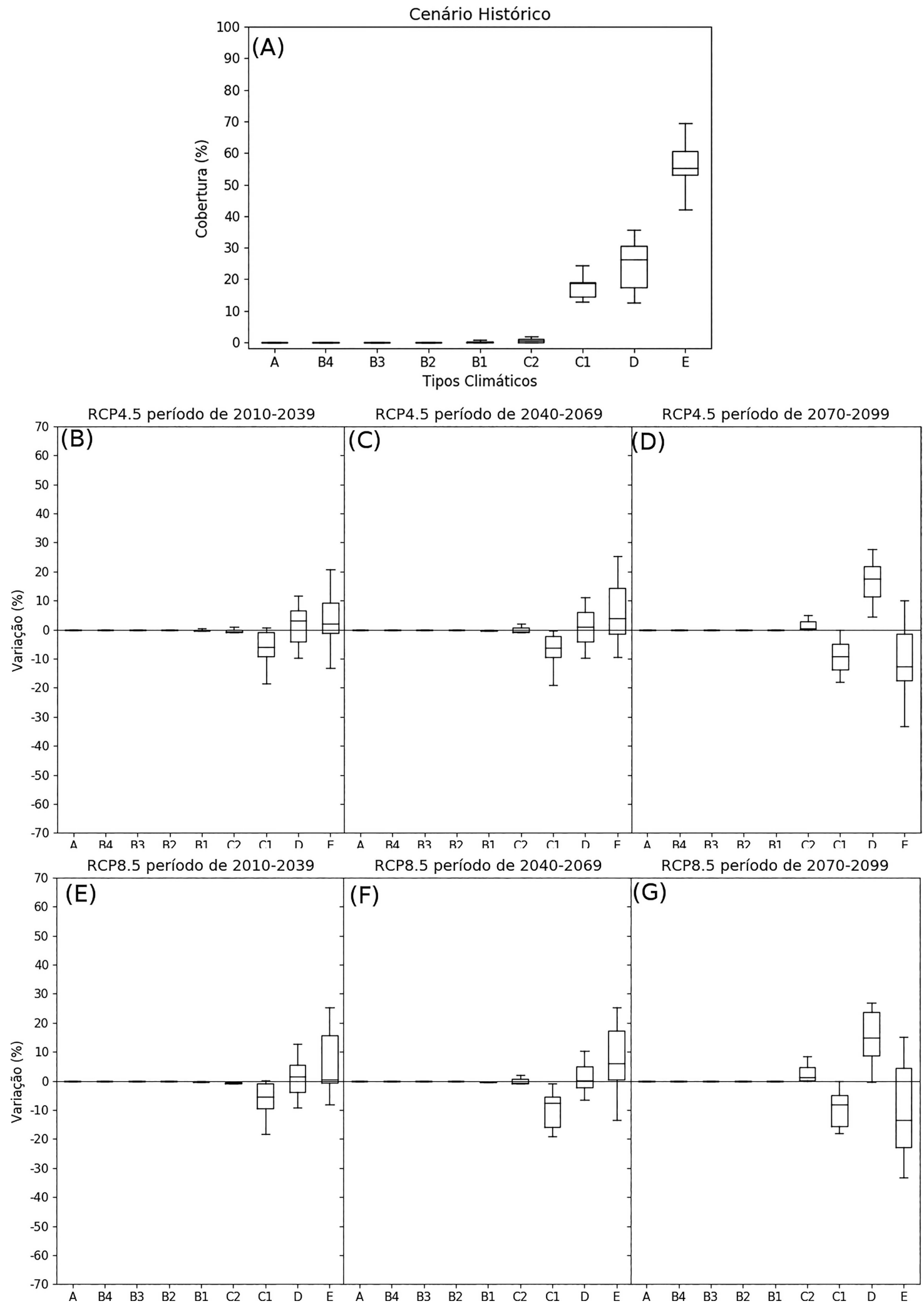

Figura 8 - Variação dos tipos climáticos na região Nordeste. (a) Área percentual de Cobertura de cada tipo de clima. Anomalia da área percentual coberta por cada tipo de clima no cenário RCP 4.5 (P45-PXX) para os períodos: (b) 2010-2039; (c) 2040-2069 e (d) 2070-2098. Anomalia da área percentual coberta por cada tipo de clima no cenário RCP 8.5 (P85-PXX) para os períodos: (e) 2010-2039; (f) 2040-2069 e (g) 2070-2098. Onde PXX, P45 e P85 representam área percentual coberta por cada tipo de clima em cada período do século. 

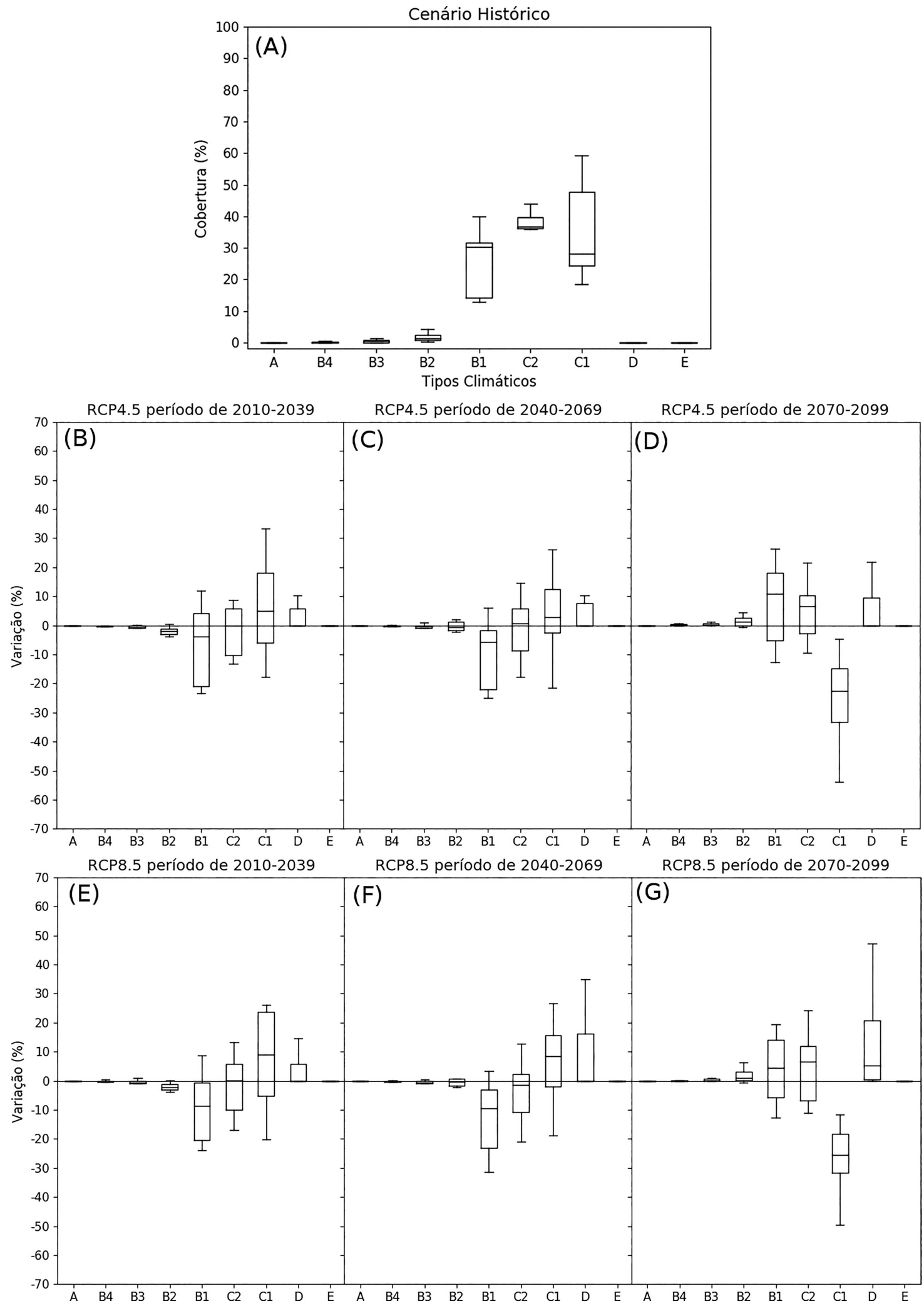

Figura 9 - Variação da classificação climática na região Norte. (a) Área percentual de Cobertura de cada tipo de clima. Anomalia da área percentual coberta por cada tipo de clima no cenário RCP 4.5 (P45-PXX) para os períodos: (b) 2010-2039; (c) 2040-2069 e (d) 2070-2098. Anomalia da área percentual coberta por cada tipo de clima no cenário RCP 8.5 (P85-PXX) pelo para os períodos: (e) 2010-2039; (f) 2040-2069 e (g) 2070-2098. Onde PXX, P45 e P85 representam área percentual coberta por cada tipo de clima em cada período do século. 
diminuição da área ocupada pelo clima B1, variando entre $-5 \%$ e $-30 \%$, no final do século. Em contraste com a redução dos climas predominantes existe um indicativo para aumento de climas áridos, em especial o D. Maiores
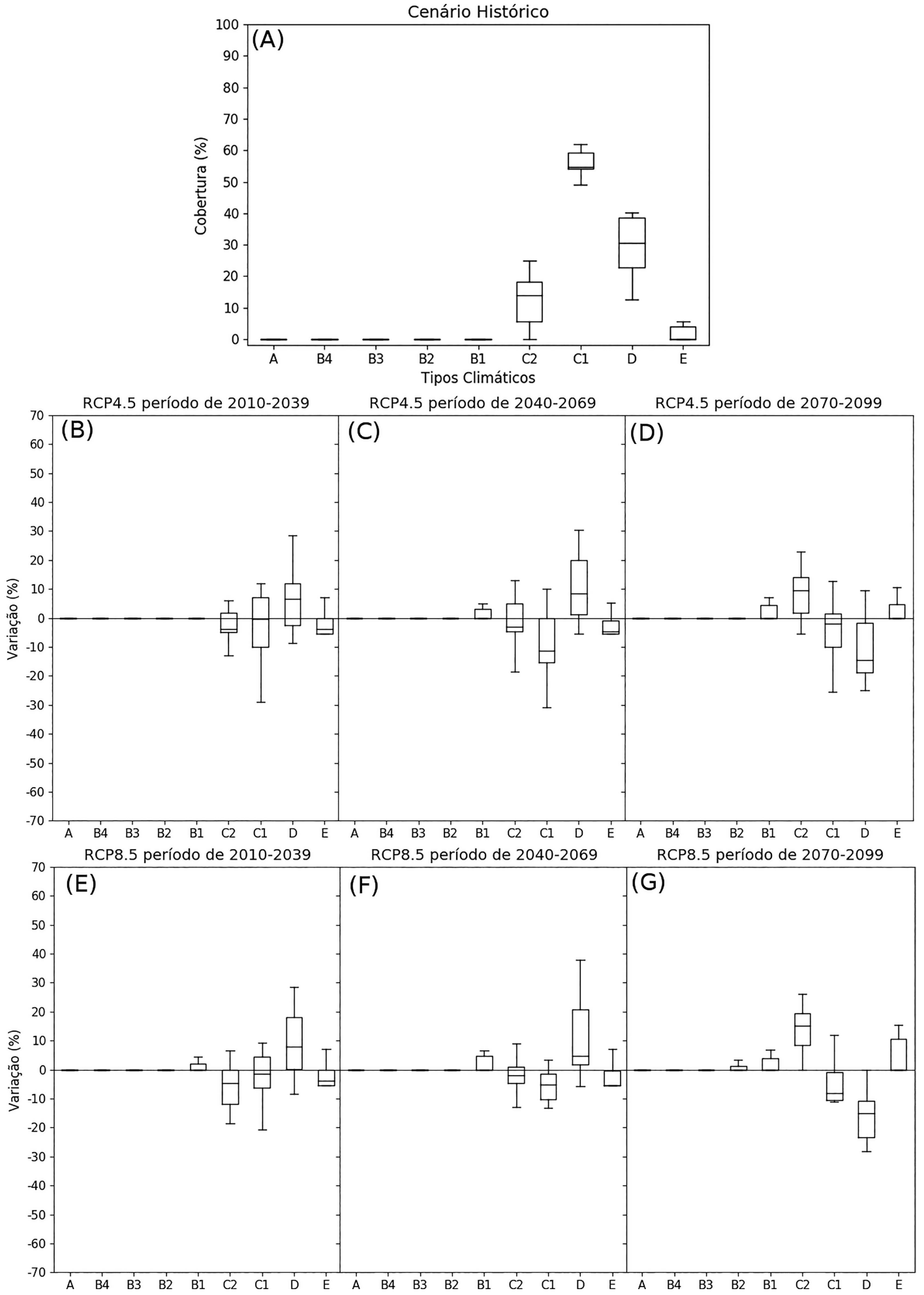

Figura 10 - Variação da classificação climática na região Sudeste. (a) Área percentual de Cobertura de cada tipo de clima. Anomalia da área percentual coberta por cada tipo de clima no cenário RCP 4.5 (P45-PXX) para os períodos: (b) 2010-2039; (c) 2040-2069 e (d) 2070-2098. Anomalia da área percentual coberta por cada tipo de clima no cenário RCP 8.5 (P85-PXX) pelo para os períodos: (e) 2010-2039; (f) 2040-2069 e (g) 2070-2098. Onde PXX, P45 e P85 representam área percentual coberta por cada tipo de clima em cada período do século. 
probabilidades de aumento da cobertura do clima D sobre a região ao longo de todo o século são indicadas pelos modelos.
O cenário RCP8.5 também projeta sobre o Norte do Brasil um expressivo aumento do tipo climático E de até $50 \%$ em relação a média histórica. $\mathrm{O}$ aumento da aridez na
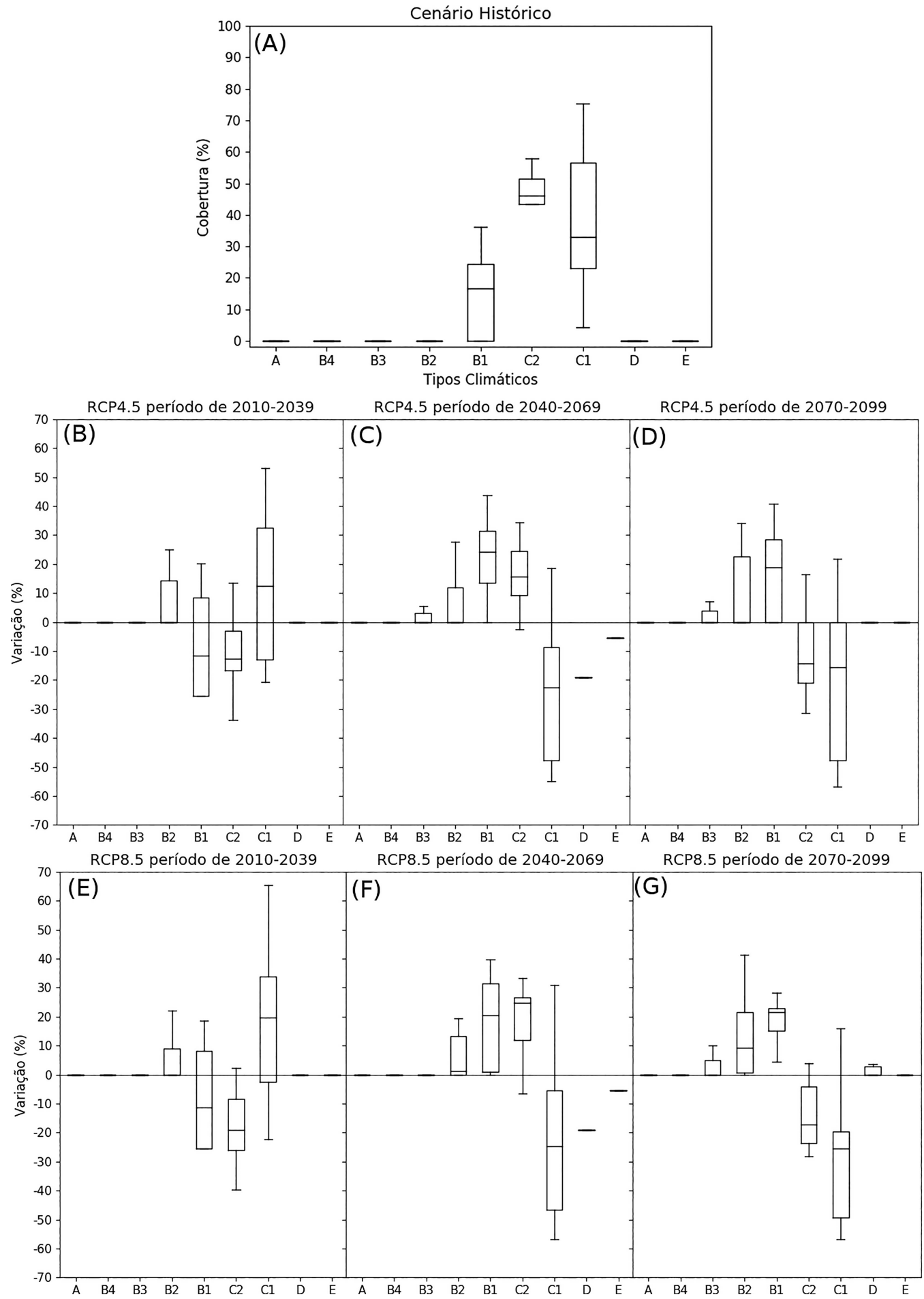

Figura 11 - Variação da cobertura dos tipos climáticos na região Sul. (a) Área percentual de Cobertura de cada tipo de clima. Anomalia da área percentual coberta por cada tipo de clima no cenário RCP 4.5 (P45-PXX) para os períodos: (b) 2010-2039; (c) 2040-2069 e (d) 2070-2098. Anomalia da área percentual coberta por cada tipo de clima no cenário RCP 8.5 (P85-PXX) pelo para os períodos: (e) 2010-2039; (f) 2040-2069 e (g) 2070-2098. Onde PXX, P45 e P85 representam área percentual coberta por cada tipo de clima em cada período do século. 
região com a maior reserva de recursos hídricos do país é preocupante, em especial para manutenção do ecossistema da Amazônia e para o setor hidrelétrico que, durante os últimos anos, tem se expandido para essa região. A redução de tais recursos pode inviabilizar a construção de novos projetos hidrelétricos na região.

Porém, na região Sudeste do país nota-se predominância do tipo climático $\mathrm{C} 1$ (entre $50 \%$ e $80 \%$ ) conforme mostrado na Fig. 10. O segundo tipo climático mais abrangente é o D (entre $20 \%$ e $30 \%$ ), que segundo a Fig. 5 concentra-se na parte mais a nordeste da região. Esta é uma região de clima complexo caracterizada por ser uma zona de transição entre os climas semiáridos (a nordeste) e úmidos (a sul).

Devido à grande incerteza das projeções para a região Sudeste, os modelos mostram grande dispersão na distribuição climática da região. Para o cenário RCP4.5 há uma redução mais acentuada a partir do segundo período avaliado dos climas do tipo $\mathrm{C} 1$ e D para a maioria dos modelos, e o aparecimento de regiões mais úmidas com climas do tipo B1 e C2. Em contrapartida, alguns modelos mostram a migração de zonas do tipo $\mathrm{C} 1$ para $\mathrm{D}$ e de $\mathrm{D}$ para $\mathrm{E}$. Indicando que possivelmente essa região responde espacialmente diferente às mudanças climáticas. $\mathrm{O}$ cenário RCP8.5 acentua o sinal destas alterações climáticas da classificação de Thornthwaite em relação ao RCP4.5, indicando um aumento dos tipos de clima $\mathrm{C} 2$ e B1 e o aparecimento de zonas com clima árido no final do século XXI.

Na Fig. 11a pode-se observar que para a região Sul do país existe uma maior dispersão entre os modelos, o que aumenta as incertezas para a região, contudo o clima do tipo $\mathrm{C} 2$ é predominante para a maioria dos modelos, chegando a cobrir mais de 55\% da região. Nesta região os modelos sugerem um aumento dos climas mais úmidos. Enquanto os tipos climáticos $\mathrm{C} 2$ e $\mathrm{C} 1$ diminuem foram observados que os tipos B2 e B1 aumentam para ambos os cenários. Estas alterações podem significar um aumento da oferta hídrica da região.

\section{Conclusões}

Os modelos do IPCC-AR5 apontam para impactos diferentes de acordo com as regiões do Brasil, indicando divergências quanto o futuro da precipitação e do escoamento superficial, contudo todos concordam com o aumento de temperatura e evapotranspiração potencial em todo território brasileiro.

Há uma maior possibilidade de aumento das regiões com climas úmidos no Sul do país, ao passo no Norte e Centro-Oeste há uma sinalização de aumento das zonas semiáridas, enquanto que na região Nordeste há uma sinalização de aumento das zonas com clima árido. Na região Sudeste existe divergência, porém a maioria dos modelos projeta aumento dos climas úmidos. Os resultados encontrados para o setor Norte concordam com os obtidos por Lucena et al. (2009), que obteve uma cenarização da matriz energética do país utilizando informações do IPCCAR4 e mencionou aumento da vulnerabilidade das regiões Norte e Nordeste do Brasil.

A tendência de aumento de climas áridos no Nordeste e Centro-Oeste do país aliado ao crescimento de demanda por água sugere que medidas estruturais, como a transposição do rio São Francisco, sejam tomadas a fim de minimizar os futuros problemas de abastecimento e conflitos pelos múltiplos usuários de água. $\mathrm{O}$ aumento de regiões úmidas no Sul do país pode representar um aumento no escoamento superficial médio e máximo, representando uma maior possibilidade de eventos extremos de cheias na região.

Devido ao aumento da ETP refletir em uma maior necessidade de água para irrigação no país, o fato destas anomalias serem mais intensas no cenário RCP8.5 indica que medidas precisam ser adotadas para minimizar a emissão de gases do efeito estufa e os impactos das mudanças climáticas, em busca de reduzir a vulnerabilidade dos sistemas hídricos brasileiros e minimizar o acirramento dos conflitos pelo uso da água no país.

Assim, as mudanças climáticas representam um desafio para a gestão de recursos hídricos, à medida que geram um conjunto de alterações que afetam o ciclo hidrológico. Além dos impactos esperados no regime hidrológico, esperam-se prováveis mudanças na demanda de diversos setores usuários. A elevação da temperatura e da evapotranspiração poderá acarretar, entre outros efeitos, maior necessidade de irrigação, refrigeração, consumo humano e dessedentação de animais em determinados períodos e regiões. Essas constatações estão associadas a um estado geral de aumento no consumo de energia, na demanda hídrica da agricultura e do abastecimento humano nos centros urbanos. Assim, as consequências das mudanças climáticas podem alterar a confiabilidade dos sistemas de água atual brasileiro e a gestão dos usos e das infraestruturas de suprimento.

\section{Referências}

ALVES, L.M.; MARENGO, J.A.; FU, R.; BOMBARDI, R.J. Sensitivity of Amazon Regional Climate to Deforestation. American Journal of Climate Change, v. 6, p. 75-98, 2017.

ANA, Agência Nacional de Águas. Conjuntura dos Recursos Hídricos no Brasil. ANA, Brasília, p. 432, 2013.

ARORA, V.K.; BOER, G.J.; FRIEDLINGSTEIN, P.; EBY, M.; JONES, C.D.; et al. Carbon-concentration and carbonclimate feedbacks in CMIP5 Earth system models. Journal of Climate, 26(15), p. 5289-5314, 2013.

BANCO MUNDIAL. Relatório sobre o desenvolvimento mundial de 2010: A mudança do clima e o desenvolvimento. World Bank, São Paulo, p. 50, 2010. 
BOMBARDI, R.J.; CARVALHO, L.M.V. Variabilidade do regime de monções sobre o Brasil: $\mathrm{O}$ clima presente e projeções para um cenário com $2 \mathrm{xCO} 2$ usando o modelo MIROC. Revista Brasileira de Meteorologia, v. 23, n. 1, p. 58-72, 2008.

BRITO, A.L.; VEIGA, J.A.P.; YOSHIDA, M.C. Extreme Rainfall Events over the Amazon Basin Produce Significant Quantities of Rain Relative to the Rainfall Climatology. Atmospheric an Climate Sciences, v. 4, p. 179-191, 2014.

CARRIL, A.F.; MENÉNDEZ, C.G.; NUÑEZ, M.N. Climate Change Scenarios over the South American Region: An Intercomprarison of Coupled General Atmosphere-ocean Circulation Models. International Journal of Climatology, v. 17, p. 1613-1633, 1997.

CAVALCANTI, I.F.A.; FERREIRA, N.J.; SILVA, M.G.A.J.; DIAS, M.A.F.S. Tempo e Clima no Brasil. Oficina de Textos, 1a ed., São Paulo, 2009.

DARELLA-FILHO, J.P.; LAPOLA, D.M.; TORRES, R.R.; LEMOS, M.C. Socio-climatic hotspots in Brazil: how do changes driven by the new set of IPCC climatic projections affect their relevance for policy? Climatic Change, v. 136, p. 413-425, 2016.

DOMINGUES, E.P.; MAGALHÃES, A.S.; RUIZ, R.M.; Cenários de Mudanças Climáticas e Agricultura no Brasil:Impactos Econômicos na Região Nordeste. Documentos Técnico-Científico, v. 42, n. 2, 2011.

EPE, EMPRESA DE PESQUISA ENERGÉTICA. Balanço Energético Nacional 2016: Ano base 2015. EPE. Rio de Janeiro. 2016

FERNANDES, R.O.; SILVEIRA, C.S.; STUDART, T.M.C.; SOUZA-FILHO, F.A. Reservoir yield intercomparison of large dams in Jaguaribe Basin-CE in climate change scenarios. Revista Brasileira de Recursos Hídricos, v. 22, p. 1-2, 2017.

FLATO, G.J.; MAROTZKE, J.; ABIODUN, B.; BRACONNOT, P., CHOU, S.C.; et al. Evaluation of Climate Models, in: Climate Change 2013: The Physical Science Basis. Contribution of Working Group I to the Fifth Assessment Report of the Intergovernmental Panel on Climate Change, edited by: STOCKER, T.F.; QIN, D.; PLATTNER, G.-K.; TIGNOR, M.; ALLEN, S. K.; et al. Cambridge and New York: Cambridge University Press, p. 741-866, 2013.

GIORGI, F.; FRANCISCO, R. Evaluating Uncertainties in the Prediction of Regional Climate Change. Geophysical Research Letters, v. 27, n. 9, p. 1295-1298, 2000.

HARGREAVES, G.H.; SAMANI, Z.A. Reference crop evaporation from temperature. Journal of Applied Engineering in Agriculture, St Joseph, v. 1, n. 2, p. 96-99, 1985.

IPCC, Intergovernmental Panel on Climate Change. Climate change 2001: Impacts, adaptation, and vulnerability. In: MCCARTHY, J.J. Contribution of Working Group II to the Third Assessment Report of the Intergovernmental Panel on Climate Change. Cambridge University Press, Cambridge, p. 1032, 2001.

IPCC, Intergovernmental Panel on Climate Change: Climate Change 2007: The physical science basis. Cambridge: IPCC, p. 18, 2007.
IPCC, Intergovernmental Panel on Climate Change. Climate Change 2014: Synthesis Report. Contribution of Working Groups I, II and III to the Fifth Assessment Report of the Intergovernmental Panel on Climate Change [Core Writing Team, R.K. Pachauri and L.A. Meyer (eds.)]. IPCC, Geneva, Switzerland, p. 151, 2014a.

IPCC, Intergovernmental Panel on Climate Change. Climate Change 2014: Impacts, Adaptation, and Vulnerability. Part A: Global and Sectoral Aspects. Contribution of Working Group II to the Fifth Assessment Report of the Intergovernmental Panel on Climate Change [Field, C.B., V.R. Barros, D.J. Dokken, K.J. Mach, M.D. Mastrandrea, T.E. Bilir, M. Chatterjee, K.L. Ebi, Y.O. Estrada, R.C. Genova, B. Girma, E.S. Kissel, A.N. Levy, S. MacCracken, P.R. Mastrandrea, and L.L. White (eds.)]. Cambridge University Press, Cambridge, United Kingdom and New York, NY, USA, p. 1132, 2014b.

LIMA, R.C.C.; CAVALCANTE, A.M.B.; MARIN, A.M.P. Desertificação e Mudanças Climáticas no Semiárido Brasileiro. Instituto Nacional do Semiárido - INSA, Campina Grande, p. 209, 2011.

LUCENA, A.F.P.; SZKLO, A.S.; SCHAEFFER, R.; SOUZA, R. R.; BORBA, B.S.M.S.; et al. The vulnerability of renewable energy to climate change in Brazil. Energy Policy, v. 37, n. 8, p. 79-89, 2009.

MARENGO, J.A.; VALVERDE, M.C. Caracterização do clima do Século XX e Cenário de Mudanças de clima para o Brasil no Século XXI usando os modelos do IPCC-AR4. Multiciência. Campinas. n. 8. 2017.

NAVARRO-RACINES, C.E.; TARAPUES-MONTENEGRO, J. E.; RAMÍREZ-VILLEGAS, J.A. Bias-Correction in the CCAFS-Climate Portal: A Description of Mehotodologies. Decision and Policy Analysis (DAPA) Research Area. International Center for Tropical Agriculture (CIAT). Cali, Colombia, 2015.

PBMC, PAINEL BRASILEIRO DE MUDANÇAS CLIMÁTICAS. Sumário Executivo do Volume 1: Base Científica das Mudanças Climáticas. Contribuição do Grupo de Trabalho 1 para o 10 Relatório de Avaliação Nacional do Painel Brasileiro de Mudanças Climáticas. Volume Especial para a Rio+20. Brasil, p. 34, 2012.

RAMIREZ-VILLEGAS, J.; CHALLINOR, A.J.; THORNTON, P.K.; JARVIS, A. Implications of regional improvement in global climate models for agricultural impact research. Environmental Research Letters, v. 8, n. 2, 2013.

ROSSATO, L. Estimativa da capacidade de armazenamento de água no solo do Brasil. INPE, São José dos Campos, 2001.

SABOIA, M.A.M.; SOUZA-FILHO, F.A.; ARAUJO-JUNIOR, L.M.; SILVEIRA, C.S. Climate changes impact estimation on urban drainage system located in low latitudes districts: a study case in Fortaleza-CE. Revista Brasileira de Recursos Hídricos, v. 22, n. 21, p. 1-15, 2017.

SCHAEFFER, R.; SZKLO, A.S.; LUCENA, A.F.P.; SOUZA, R. R.; BORBA, B.S.M.C.; et al. Mudanças climáticas e segurança energética no Brasil. PPE-UFRJ, Rio de Janeiro, p. 35, 2008.

SHIKLOMANOV, I.A. World water resources at the beginning of the 21 st century. International Hydrological Series. v. 31, n. 3 , p. $435,1998$. 
SILVEIRA, C.S.; SOUZA-FILHO, F.A.; COSTA, A.A.; CABRAL, S.L. Avaliação de desempenho dos modelos do CMIP5 quanto à representação dos padrões de variação da precipitação no século XX sobre a região Nordeste do Brasil, Amazônia e bacia do Prata e análise das projeções para o cenário RCP8.5. Revista Brasileira de Meteorologia, v. 28, n. 3, p. 317-330, 2013.

TAYLOR, K.E.; STOUFFER, R.J.; MEEHL, G.A. An Overview of CMIP5 and the experiment design. Bull. Amer. Meteor. Soc., v. 93, n. 4, p. 485-498, 2012.

THORNTHWAITE, C.W. An approach toward a rational classification of climate. Geographical Rev., v. 38, n. 1, p. 55-94, 1948.

THORNTHWAITE, C.W.; MATHER, J.R. The water balance. Centerton, Drexel Institute of Technology-Laboratory of Climatology. Publications in Climatology, v. 8, n. 1, p. 104, 1955.

TURCO, M.; VON HARDENBERG, J.; PALAZZI, E.; PROVENZALE, A. Regional climate projections and bias correction methods over the Greater Alpine Region. NexData Report. 2015.

TORRES, R.R.; LAPOLA, D.M.; MARENGO, J.A.; LOMBARDO, M.A. Socio-climatic hotspots in Brazil. Climatic Change, v. 115, n. 3-4, p. 597-609, 2012.

TORRES, R.R.; MARENGO, J.A. Climate change hotspots over South America: from CIMP3 to CMIP5 multi-model datasets. Theoretical and Applied Climatology, v. 117, n. 3-4, p. $579-587,2014$.

VAN VUUREN, D.P.; EDMONDS, J.; KAINUMA, M.; RIAHI, K.; THOMSON, A.; et al. The representative concentration pathways: an overview. Climatic Change, v. 109, n. 1-2, p. 5-11, 2011.
VERA, C.; SILVESTRI, G.; LIEBMANN, B.; GONZÁLEZ, P. Climate change scenarios for seasonal precipitaion in South America from IPCC-AR4 models. Geophysical Research Letters, v. 33, n. 13, 2006.

VOLOSCIUK, C.; MARAUN, D.; VRAC, M.; WIDMANN, M. A combined statistical bias correction and stochastic downscaling method for precipitation. Hydrology and Earth System Sciences, v. 21, n. 3, p. 1693-1719, 2017.

WIEDER, W.R.; BOEHNERT, J.; BONAN, G.B.; LANGSETH, M. Regrided Harmonized World Soil Database v1.2. Oak Ridge National Laboratory Distributed Active Archive Center, Oak Ridge, v. 1, 2014.

\section{Sítios da Internet}

CRU, CLIMATIC RESEARCHH UNIT. Data base, disponível em: http://badc.nerc.ac.uk/data/cru/. Acesso em: 05 ago. 2015.

FAO/IIASA/ISRIC/ISSCAS/JRC, 2012. Harmonized World Soil Database (version 1.2). FAO, Rome, Italy and IIASA, Laxenburg, Austria. Disponível em: http://webarchive.iiasa.ac. at/Research/LUC/External-World-soil-database/HTML/. Acesso em: 20 maio de 2017.

UEA, UNIVERSITY EAST ANGLIA. Climatic Research Unit. CRU. Disponível em: http://www.cru.uea.ac.uk/. Acesso em: 05 ago. 2015.

This is an Open Access article distributed under the terms of the Creative Commons Attribution Non-Commercial License which permits unrestricted non-commercial use, distribution, and reproduction in any medium provided the original work is properly cited. 